\title{
El «modelo» norteamericano en la reglamentación de las intervenciones federales en la Argentina decimonónica. Debates en el Congreso Nacional (1869 y 1894$)^{*} /$
}

\author{
The American «Model» in the Regulation of Federal \\ Interventions in $19^{\text {th }}$ Century Argentina. Debates \\ in the National Congress (1869 and 1894)
}

\author{
Laura Cucchi \\ ORCID iD: http://orcid.org/0000-0002-6454-0343 \\ Ana L. Romero \\ ORCID iD: http://orcid.org/0000-0003-4269-1893
}

Universidad de Buenos Aires / CONICET

Este trabajo examina el lugar de la legislación de los Estados Unidos como referencia doctrinal en los dos mayores debates legislativos de la Argentina decimonónica acerca de la reglamentación de las facultades del gobierno nacional para intervenir en las provincias.

Palabras Clave: Argentina; Intervención Federal; Congreso Nacional; Jurisprudencia, Estados Unidos.

This paper studies the role played by American Constitutional Law as doctrinal reference during legislative and public debates on the regulation of the national government's powers to intervene in provincial affairs in 19th century Argentina.

KeYwords: Argentina; Federal Intervention; National Congress; Jurisprudence; United States.

Copyright: () 2017 CSIC. Este es un artículo de acceso abierto distribuido bajo los términos de una licencia de uso y distribución Creative Commons Attribution (CC-by) España 3.0.

* Este trabajo ha sido realizado en el marco del proyecto PICT 2234/2013: «La construcción del sistema político argentino. El modelo norteamericano en los debates legislativos durante las décadas de 1870 y 1890», dirigido por la Dra. Laura Cucchi y financiado por la Agencia Nacional de Promoción Científica y Tecnológica. Periodo: 2014-2016. Agradecemos también los generosos comentarios que la Dra. Valentina Ayrolo realizó a una versión previa de este texto. 


\section{Presentación}

Los Estados Unidos constituyeron el principal referente republicano para la formación de los estados hispanoamericanos que se organizaron tras las independencias de comienzos del siglo XIX. En la Argentina, ese «modelo» ${ }^{1}$ fue fundamental para edificar la república representativa federal diseñada por la primera Constitución nacional de 1853 que rige, con reformas, hasta nuestros días. Sin embargo, sobre el final del siglo Estados Unidos perdió ese status de modelo jurídico, en el marco de crecientes críticas contra el funcionamiento del régimen federal. ${ }^{2}$ Entonces, la jurisprudencia nacional comenzó a competir con el ejemplo norteamericano y Estados Unidos pasó a ocupar un rol de referente histórico más que jurídico.

Este trabajo examina los usos de la doctrina norteamericana en la práctica parlamentaria argentina y explora los cambios en su utilización que se dieron entre la organización nacional y el fin de siglo, tomando como mirador los debates que giraron en torno a la reglamentación de la facultad del gobierno nacional de intervenir las provincias en casos de conmoción interna o ataque externo. Esa competencia, que había sido creada por la Constitución norteamericana, fue incorporada con distintos matices por varias naciones hispanoamericanas que adoptaron el esquema federal. ${ }^{3}$ En la Argentina este principio fue consagrado en el artículo sexto de la Constitución nacional ${ }^{4}$ y aplicado en más de cincuenta ocasiones durante el siglo XIX, pero su implementación estuvo acompañada de profundos desacuerdos respecto de cuáles eran los alcances de las competencias del poder nacional, y a cuál de los poderes públicos (ejecutivo o legislativo) correspondían. Esas

1 Nos referimos al conjunto de doctrina constitucional y jurídica norteamericana laxamente como modelo, a pesar de los desacuerdos que tenían lugar en Estados Unidos sobre el funcionamiento político e institucional de la república federal. Esos desacuerdos fueron recuperados en la Argentina y alimentaron a su vez las controversias sobre los dilemas que el país estaba enfrentando para la organización de su sistema político. Sobre la historia norteamericana del periodo: Bender, 2006.

2 Chiaramonte y Buchbinder, 1992.

3 Sola, 1982. Sobre el régimen federal en la Argentina: Botana, 1993. Alonso y Bragoni, 2015.

4 La carta de 1853 estableció que «El Gobierno Federal interviene con requisición de las Legislaturas o Gobernadores provinciales, o sin ella, en el territorio de cualquiera de las Provincias, al solo efecto de restablecer el orden público perturbado por la sedición, o de atender a la seguridad nacional amenazada por un ataque o peligro exterior». Posteriormente, durante la reforma constitucional de 1860 que acompañó la incorporación de Buenos Aires a la Confederación Argentina se reformó el artículo para preservar la autonomía de esa provincia frente al poder nacional y quedó redactado así hasta la actualidad: «El gobierno federal interviene en el territorio de las provincias para garantir la forma republicana de gobierno, o repeler invasiones exteriores, y a requisición de sus autoridades constituidas para sostenerlas o restablecerlas, si hubiesen sido depuestas por sedición, o por invasión de otra provincia». Sommariva, 1931, 5-9 y 19-25. 
controversias plantearon la necesidad de sancionar una ley reglamentaria del mencionado artículo constitucional, iniciativa que el Congreso encaró en varias ocasiones pero que solo en dos momentos tuvo alcances políticos decisivos. El primero se produjo en 1869-1870 en el marco de los intentos del poder nacional de subordinar al conjunto de las provincias para consolidar el naciente estado, y el segundo se dio varias décadas después, en los años noventa, en el marco de una profunda crisis política. En esas dos instancias, la historia constitucional de los Estados Unidos funcionó como el espejo frente al cual las dirigencias evaluaron la situación argentina y defendieron cursos de acción diversos y, en ocasiones, opuestos.

\section{La centralidad del modelo norteamericano en la temprana experiencia constitucional}

El ejemplo estadounidense tuvo un decisivo impacto en el diseño constitucional de las repúblicas hispanoamericanas durante el siglo XIX. ${ }^{5}$ En el caso argentino, los estudios sobre esas apropiaciones se han concentrado en las polémicas que acompañaron la sanción de la Constitución en 1853, ${ }^{6}$ pero han prestado menor atención al peso que ese ejemplo tuvo, en las décadas siguientes, en la traducción práctica de los preceptos constitucionales a un corpus legislativo que normara específicamente algunos principios por ella enunciados. Esto ha hecho perder de vista que en el marco de esa labor parlamentaria se apeló constantemente a los argumentos brindados por los publicistas norteamericanos, que fueron incorporados y traducidos a las necesidades de la organización política nacional. ${ }^{7}$ Por ese motivo, en los años sesenta y comienzos de los setenta se impulsó la traducción y circulación de los principales tratados de teoría política y constitucional norteamericana, pues como sintetizaba el traductor argentino de la obra de Kent:

las dificultades y embarazos con que actualmente tropiezan los poderes creados por la Constitución, en el ejercicio de sus atribuciones, no podrán ser allanados mientras no se difunda y facilite en la República un perfecto conocimiento de la naturaleza de dichos poderes, así como nociones claras acerca de la estension de sus facultades [...] estas tan recientes instituciones continuarán siendo letra muerta, hasta que una autorizada jurisprudencia no venga a definir las dudas y esclarecer los puntos oscuros del código fundamental. ${ }^{8}$

5 Entre otros: Aguilar Rivera, 2000. Botana, 1984.

6 Especialmente Botana, 1984. Adelman, 2007.

7 Zorraquín Becú, 1976. Sola, 1982. Zimmermann, 2014.

8 Kent, 1865, II-III. 
Con esos objetivos, el poder ejecutivo nacional adquirió y fomentó la traducción de las obras de Alden, Cushing, Grimke, Kent, Paschal, Story y Tiffany, entre otros, y las distribuyó entre legisladores, funcionarios, universidades, bibliotecas y juzgados de distintas provincias. Esas ediciones en español, acompañadas de estudios introductorios, fueron elaboradas por reconocidos publicistas que buscaron demostrar la utilidad de la experiencia de los Estados Unidos para la edificación del sistema político argentino. ${ }^{9}$ Junto con el impacto directo de los libros, la difusión de esas doctrinas entre una parte importante de la clase política fue alimentada por la circulación de revistas especializadas, la incorporación de obras de derecho norteamericano al currículum de los colegios nacionales desde 1863 y el establecimiento de las cátedras de Derecho Constitucional en las universidades de Córdoba (1858) y Buenos Aires (1868).

Ese impacto de la doctrina constitucional de los Estados Unidos se hizo evidente durante el primer debate de amplias proporciones acerca la necesidad de reglamentar el artículo sexto. Este se produjo en 1868, a comienzos de la presidencia de Domingo F. Sarmiento, como consecuencia de la intervención de la provincia de San Juan. ${ }^{10}$ En esa crisis política, que hizo evidentes tensiones y disputas entre los poderes públicos nacionales así como entre el ejecutivo nacional y los ejecutivos provinciales, se enfrentaron dos grandes posturas. La primera, expresada por el ex presidente Bartolomé Mitre, ${ }^{11}$ defendía la facultad exclusiva del Congreso de decidir la intervención en los casos (como el sanjuanino) en que peligrara la forma republicana de gobierno, mientras entendió que el ejecutivo tenía la potestad de hacerlo en los demás casos previstos por el artículo sexto, durante el receso parlamentario y a condición de rendir cuentas al Congreso cuando reiniciara sus sesiones. ${ }^{12}$ La otra postura fue sostenida por los ministros nacionales que estuvieron presentes en el recinto y defendieron la facultad del ejecutivo de intervenir en todos los casos detallados por el artículo constitucional, señalando que al Congreso tocaba completar esa acción otorgando las herramientas materiales asociadas a las intervenciones: cuerpos de

9 Zimmermann, 2014.

10 Sarmiento no representaba entonces a ningún partido y había llegado a la presidencia impulsado por un grupo de oficiales del Ejército y por un acuerdo entre elementos del partido nacionalista de Mitre y del otro partido de Buenos Aires, el autonomista.

11 Líder del partido liberal nacionalista de Buenos Aires, que había estado a la cabeza de la organización nacional a partir de la unión de esa provincia a la Confederación Argentina en 1861.

12 Las sesiones ordinarias se extendían del $1^{\circ}$ de mayo al 30 de septiembre. El receso parlamentario daba así un amplio margen de acción al ejecutivo. 
milicias y recursos materiales. La primera posición afirmaba el poder del legislativo de actuar siempre que la Constitución mencionara ambiguamente al «gobierno federal», mientras que la segunda arguiía que la carta nacional no daba esas potestades al legislativo porque, de haberlo querido hacer, las hubiera mencionado en los capítulos en que se refería explícitamente a las facultades del Congreso. La letra de la Constitución y sus opacidades alentaron así las controversias.

Al año siguiente, y por iniciativa de Mitre, los diputados Manuel Quintana por Jujuy y Santiago Cáceres y Nicéforo Castellanos por Córdoba presentaron dos proyecto de leyes reglamentarias ${ }^{13}$ que precisaban el alcance del artículo constitucional y que buscaban así eliminar las arbitrariedades en la materia. ${ }^{14}$ Aunque las dos fueron aprobadas por el legislativo, el ejecutivo las vetó y presentó una contrapropuesta que tampoco fue aceptada por las cámaras. ${ }^{15}$ ¿Qué diferenciaba las propuestas? Una vez más, hacían una lectura distinta de lo estipulado por el artículo sexto que otorgaba la facultad de la intervención al «gobierno federal». A pesar de la ambigüedad de la fórmula, en la práctica las intervenciones habían funcionado en la mayoría de los casos como prerrogativa del ejecutivo (aunque las había dispuesto en general durante el receso legislativo). Frente a esa situación de hecho, las dos leyes reglamentarias sancionadas por las cámaras concentraban en el legislativo las facultades federales de intervenir en el territorio de las provincias. Solamente se autorizaba al ejecutivo a decretar la intervención durante el receso del legislativo — que en los primeros días de sesiones debía aprobar o rechazar el curso de acción del presidente- y a movilizar las milicias necesarias y efectuar gastos en los casos menos controversiales: para ejecutar leyes del Congreso, sofocar guerras interprovinciales e invasiones exteriores. De este modo se procuraba mantener al ejecutivo fuera del «régimen interno de las Provincias» y evitar así «la omnipotencia de los gobiernos». ${ }^{16}$ Explícitamente se establecía que esa norma no constituía una «ley orgánica» puesto que «la razón aconsejaba postergar el trabajo

13 Las leyes «reglamentarias» apuntaban a regular los mecanismos de realización del artículo sexto y establecían la necesidad de que en cada caso de intervención se sancionara una ley particular. En cambio, las «orgánicas o generales» buscaban establecer de manera general los mecanismos de intervención y desechar la necesidad de discusión legislativa en cada caso.

14 Congreso Nacional/Diputados, 1869, 173 (sesión del 21 de julio). Botana (1998, 124) menciona que los proyectos de ley fueron elaborados por Mitre y luego presentados al Congreso por esos tres diputados aliados. Como antecedente se encontraban varios proyectos parlamentarios de los años cincuenta y sesenta (Sommariva, 1931).

15 Remorino, 1954, 489.

16 Congreso Nacional/Diputados, 1869, 222 (sesión del 6 de agosto). 
de una ley general y completa, y consignar aquellas normas precisas que fuesen más necesarias, supeditando a la experiencia del porvenir la fijación de otras reglas que completasen la doctrina». ${ }^{17}$ Los miembros del Congreso consideraban así que estas dos leyes solo debían regir provisoriamente hasta que llegara el momento de sancionar una normativa general en la materia.

Por el contrario, la propuesta de Sarmiento era sancionar una ley orgánica o general (pues el presidente era particularmente crítico de la idea de dictar «una ley de circunstancia») que fortaleciera las atribuciones del ejecutivo nacional. Para ello, propuso adoptar una ley norteamericana: la Militia Act de $1795^{18}$ que reglamentó la garantía federal establecida en el artículo cuarto de la Constitución de esa nación, y que había sido escasamente invocada y aplicada hasta la guerra civil y la reconstrucción. El ejecutivo fundó esta propuesta en la ventaja que suponía «una práctica conocida y los resultados de la experiencia», oponiéndola así a un proyecto derivado simplemente de ideas de los legisladores:

La jurisprudencia norte-americana se halla basada en esta parte sobre la ley de 1795; de suerte que si adoptamos nosotros un sistema opuesto, habríamos perdido esta guía tan segura en nuestra marcha, para entregarnos sin reglas fijas a lo arbitrario en las ideas, que no tarda en traer tras de sí como consecuencia inevitable, la arbitrariedad de los hechos, que se quiere precisamente evitar. ${ }^{19}$

El presidente consideraba que aunque había una variedad de posturas teóricas y preferencias políticas de los legisladores sobre cómo debía funcionar el régimen federal, en la práctica solo Estados Unidos había probado con éxito el sistema, y en ese sentido su legislación y práctica federal constituía una guía más segura que la más breve historia nacional y los antecedentes casuísticos de las intervenciones a las provincias argentinas realizadas entre 1853 y su presidencia. Para llevar la cuestión lejos del terreno político, proponía al Congreso realizar a través del ministro plenipotenciario en Washington una consulta sobre los alcances de la mencionada ley «a los constitucionalistas más distinguidos tales como Curtis, Reverdy, Johnson, Pomeroy y Sumner, u otros que sean la más alta expresión intelectual de los diversos partidos de la Unión». Ese diálogo podía ofrecer al

17 Sommariva, 1931, 380.

18 Se trataba de una ley que estipulaba los casos en que el presidente podía movilizar las milicias de los estados para ejecutar leyes de la Unión, repeler invasiones y suprimir rebeliones. Su antecedente eran las leyes de milicias de 1792 que por primera vez habían fijado los poderes del ejecutivo en esta materia.

19 Congreso Nacional/Senado, 1869a, 594 (sesión del 21 de agosto). 
Congreso argentino una puesta al día de las principales polémicas y resultados en materia de garantía federal y permitir que la sanción de la ley se enmarcara en «una esfera científica, imparcial, elevada». ${ }^{20}$

$\mathrm{Su}$ propuesta, que copiaba enteramente el texto norteamericano, daba vastas facultades de intervención al ejecutivo en las provincias para garantizar la «seguridad pública». Establecía que el presidente podía movilizar a las milicias en caso que debiera contenerse una invasión o sofocar una insurrección «sin que la presencia o el receso del Congreso introduzca modificación alguna en su ejercicio». ${ }^{21}$ De esta manera, no solo impugnaba el proyecto de las cámaras de fortalecer las facultades del legislativo, sino que buscaba eliminar la práctica de sanción legislativa de las intervenciones. Con ese objeto, el presidente argumentaba que era necesaria una ley orgánica de carácter general, pues

no puede, no debe preceder ley del Congreso para acordar lo que la Constitución tiene acordado; suponer que cada vez que se requiera proteger, intervenir para restablecer, se ha de dictar una ley especial, es suponer que fuera motivo de deliberación el cumplir o no con las garantías y las disposiciones textuales expresas en la Constitución. ${ }^{22}$

Para reforzar esta propuesta adjuntaba además una nota del ministro plenipotenciario de los Estados Unidos en Buenos Aires al ministro de Relaciones Exteriores, en la que el primero daba cuenta de las facultades presidenciales en Estados Unidos «para intervenir en los negocios internos de un estado bajo ciertas circunstancias», práctica que, según mencionaba, había sido llevada a cabo desde los primeros presidentes hasta las más recientes necesidades impuestas por la guerra civil: «Negar ese derecho es asegurar que existe en las provincias o Estados igual o superior autoridad a la del Gobierno Federal [...] doctrina odiosa para nosotros pues nos ha envuelto en la última terrible guerra». ${ }^{23}$ Así, al mismo tiempo que apuntalaba las pretensiones del ejecutivo argentino, daba cuenta también de las dificultades y controversias que la fórmula federal había generado en su país.

20 Ibidem, 593.

21 Idem. Así, mientras para Sarmiento y para Varela la Militia Act de 1795 no establecía límites por parte del Congreso a la facultad presidencial de movilizar milicias, Mitre subrayaba que en su artículo segundo la mencionada ley indicaba «que la milicia así convocada, podía continuar en servicio únicamente hasta los treinta días posteriores a la apertura de las sesiones legislativas. Esto importa tanto como decir, que, en presencia del Congreso, el Presidente no puede convocar las milicias sin su autorización espresa, cesando por el hecho la autorización que únicamente responde a la época del receso» (Congreso Nacional/Senado, 1869b, 22).

22 Sommariva, 1931, 384.

23 Congreso Nacional/Senado, 1869a, 597 (sesión del 21 de agosto). 
Se ha sugerido que esta posición que tuvo Sarmiento durante su presidencia acerca de la relación gobierno central/provincias se vinculó a un cambio «oportunista». Este publicista, que había defendido la tesis autonomista en la convención constituyente de 1860, se inclinó posteriormente por la organización de un Estado central fuerte. ${ }^{24}$ Recientemente se ha señalado que ese cambio pudo haberse ligado también a las modificaciones que se dieron en la política norteamericana, que él seguía tan de cerca, como consecuencia de la guerra civil. ${ }^{25}$ En lo que refiere puntualmente a la reglamentación de las intervenciones, consideramos que en ese cambio de posición de Sarmiento influyó también la apelación que Lincoln hizo de la garantía federal en sus acciones militares contra el Sur, al considerar que la secesión era inconstitucional por lo cual los estados del Sur seguían perteneciendo a la unión y simplemente se hallaban en rebeldía. ${ }^{26}$ Por ello apeló a la garantía federal y a la ley de 1795 (la misma que Sarmiento propuso copiar) cuando movilizó milicias en 1861: «En otras palabras, se trataba de un caso de insurrección interna, una rebelión llevada a cabo por ciudadanos criminales, no de una guerra entre naciones». ${ }^{27}$

En sintonía, la propuesta de Sarmiento de afirmar las prerrogativas del ejecutivo en materia de intervención se ligaban a su preocupación por asegurar la obediencia al poder nacional en el conjunto del territorio, y específicamente con su programa en pos de terminar con focos de poder en distintas provincias, que actuaban con independencia del gobierno nacional y socavaban su autoridad y capacidad de mando. ${ }^{28}$ En su veto a las leyes sancionadas por cámaras pesaron esas preocupaciones sobre la obediencia y el orden en las provincias y su programa de un gobierno «fuerte», que se vinculaban con sus aspiraciones políticas personales pero las excedían. Asimismo, el rechazo de las cámaras al proyecto del ejecutivo puede haberse ligado a varios factores: al «espíritu de cuerpo» denunciado por el presidente, a desacuerdos en los modos que se entendía debía operativizarse la fórmula federal y las prerrogativas que correspondían en ese marco a cada uno de los poderes públicos, así como al hecho de que el Congreso fuera entonces el espacio de expresión de la oposición liderada por Mitre.

24 Sommariva, 1931, 356. Botana, 1998, 124.

25 Zimmermann, 2014.

26 Jaffa, 2004, 197-198.

27 Mc Pherson, 2009, 74-75.

28 Sobre los desafíos a estabilidad política de la Argentina en las primeras décadas de vida constitucional: Halperin Donghi, 1995. Bragoni y Míguez, 2010. 
Tal vez esos factores expliquen por qué no se alcanzó un punto de acuerdo entre las dos posturas. El ejecutivo podría haber aceptado las leyes si el Congreso hubiera limitado sus facultades exclusivas a los casos de subversión de la forma republicana de gobierno y hubiera concedido que en el resto de los casos previstos por el artículo sexto podía intervenir el ejecutivo. ${ }^{29}$ Pero el Congreso no tomó ese camino y buscó tener mayores atribuciones, lo cual dificultó las negociaciones en un tema ya de por sí muy complicado, pues condensaba tensiones verticales entre provincias y gobierno central con fricciones horizontales entre los poderes nacionales. Las dos cuestiones se cruzaban y confundían pero no eran equivalentes. Al Congreso le preocupaba la relación ejecutivo/legislativo y quería demarcar sus atribuciones. En cambio, Sarmiento sentía más urgencia por definir la relación gobierno central/provincias, y fortalecer al poder ejecutivo dotando al presidente y sus ministros de la libertad suficiente para que su acción frente a crisis en las provincias pudiera ser «rápida, vigorosa y eficaz». ${ }^{30}$

Con preocupaciones y agendas diversas, el presidente, sus ministros y los miembros del Congreso apelaron a la legislación y práctica constitucional de la nación del Norte. Esa jurisprudencia estructuró los argumentos sostenidos por los contendientes, demostrando la importancia de la labor de difusión de la historia constitucional norteamericana para la organización institucional de la Argentina. ${ }^{31}$ De los libros que unos y otros llevaron al recinto y de los folletos con fragmentos de obras que fueron repartidos, los más utilizados se dividieron en tres grupos. Unos fueron considerados «antiguos» por los oradores: El Federalista, que en otros países de habla hispana había tenido traducciones parciales pero aun no había sido editado completo en español; John Ticknor Curtis, Historia del origen, formación y adopción de la Constitución de los Estados Unidos, original de 1854 y traducción de 1866; Luther S. Cushing, Manual of Parliamentary Practice: Rules of Proceeding and Debate in Deliberative Assemblies, publicada en 1854 y no traducida aun; James Kent, Del gobierno y jurisprudencia constitucional de los Estados Unidos, original también de 1854 y traducción de 1865; Joseph Story, Comentarios a la Constitución Federal de los Estados

29 Sommariva, 1931.

30 Congreso Nacional/Senado, 1869b, 593 (sesión del 12 de agosto).

31 Algunos representantes descartaron el uso de tratados norteamericanos, pues «esos libros: son parciales, apasionados» y en ellos también se encontraban contenidas las disputas contemporáneas entre el Congreso y el presidente de Estados Unidos. Por ejemplo, el senador por San Juan, Tadeo Rojo, declaró: «Nosotros tenemos nuestro libro, la Constitución, y en ella debemos estudiar para formar nuestros juicios». Congreso Nacional/Senado, 1869a, 167 (sesión del 26 de junio). 
Unidos, original de 1833 y traducción de 1860 . Pero también se refirieron a autores que denominaron «modernos» y a obras contemporáneas o posteriores a la guerra civil: William Whiting, The War Powers of the President of the United States and the Legislative Powers of Congress in Relation to Rebellion, Treason and Slavery, publicada en 1862 y traducida en Buenos Aires en 1869; George Paschal, The Constitution of the United States. Defined and carefully anotated, publicada en 1868 unos meses antes del debate y sin edición hispana; John Norton Pomeroy, An Introduction to the Constitutional Law of the United States, también publicada en 1868 y sin traducción en ese momento. Un tercer grupo los constituyeron otras fuentes como los United States Statutes at Large, que habían comenzado a publicarse 1845, y por supuesto la Constitución de los Estados Unidos y las de sus estados. El único otro ejemplo nacional recuperado en el debate fue el de Suiza y se remitió al Acta federal elaborada por Pellegrino Rossi.

Esos libros fueron citados por todos aquellos que intervinieron en las polémicas, para defender posiciones diversas y en ocasiones completamente opuestas. Como resumía el ministro de Relaciones Exteriores:

Refutando esos discursos [de Mitre] apoyaré mi doctrina, y desarrollaré mi pensamiento. Para ello, voy a servirme mucho de mi biblioteca, señor Presidente, pidiendo disculpas al Senado si molesto su atención. No debe extrañarse que yo me sirva de los libros para dar autoridad a mi palabra, cuando el señor Senador por Buenos Aires, hombre de gobierno, constitucionalista consumado, ha sentido la misma necesidad que yo, apoyando la mayor parte de sus argumentos en autores americanos, los mismos que yo voy a citar. ${ }^{32}$

Los polemistas hicieron referencia también a sentencias de la Corte Suprema de Estados Unidos. En especial remitieron a «Luther vs. Borden», el fallo que la Corte promulgó en 1849 en relación a un conflicto desatado en Rhode Island durante la rebelión de Dorr en 1842, que derivó en la organización de dos gobiernos. ${ }^{33}$ El presidente de la Corte, Roger B. Taney, afirmó entonces que el presidente y el Congreso debían tomar la decisión

32 Ibidem, 214.

33 En 1841 la Constitución de Rhode Island solo concedía voto a los terratenientes que representaban una octava parte de la población. Una convención popular impugnó esas condiciones y convocó a la elección de autoridades con una nueva reglamentación que otorgaba derechos políticos amplios. En ella fue elegido Thomas W. Dorr, y comenzaron a funcionar dos legislaturas y dos poderes ejecutivos. Dorr tomó control del noroeste del Estado e inició una acción militar a la que el gobernador conservador en ejercicio, Samuel Ward King, respondió dictando la ley marcial. King requirió además el apoyo del presidente Tyler, quien «aunque la causa era muy antipática, éste lo prometió para cuando fuese indispensable». Finalmente «la fuerza del Estado los dispersó antes de que la protección federal se formalizase» (Sommariva, 1935, 12-13). 
respecto de cuál de los era el legítimo, y que el poder judicial no tenía injerencia alguna en el asunto.

La utilización de ese célebre fallo por las dos partes en debate ilustra cómo las mismas fuentes de autoridad eran invocadas para argumentos opuestos. Mitre señaló que Taney había establecido la supremacía del legislativo sobre el ejecutivo al indicar que incluso cuando el presidente utilizara las facultades conferidas por la Militia Act de 1795, esa era una ley reglamentaria dictada por el Congreso de los Estados Unidos y no una facultad otorgada al presidente directamente por la Constitución. ${ }^{34}$ Por ello, el Congreso tenía poderes para revisar y en caso necesario rectificar la acción presidencial, tal como lo había expresado también otro tratadista recuperado por Mitre, George Paschal. Armado con estos argumentos, el ex presidente concluía:

Por consecuencia, según las declaraciones de esta sentencia que hace jurisprudencia constitucional en los Estados Unidos, la facultad que nos ocupa pertenece originalmente al Congreso: él puede reglamentarla, puede delegarla o darla, o hacer de ella el uso que cree más conveniente dentro de los límites de sus facultades legislativas [...] al Congreso toca determinar los medios de hacer efectiva la garantía, y por lo tanto de reglamentarla, desprendiéndose de más o menos poder. ${ }^{35}$

En esta línea de argumentación, al no haberse dictado todavía ninguna ley reglamentaria de intervenciones federales, el Congreso retenía todas las facultades en la materia. Frente a esto, el senador por La Rioja, Abel Bazán, respondió a Mitre que Taney se había limitado a afirmar que, cuando debía admitirse a un estado en la Unión, correspondía al Congreso evaluar que allí funcionara la forma republicana de gobierno: «Esto es, todo lo que importa el juicio del Juez Taney». ${ }^{36}$

Posiciones opuestas fueron así defendidas de la mano de la misma jurisprudencia norteamericana, demostrando la importancia que todos los legisladores, más allá de su posición política, dieron a esas fuentes jurídicas durante las primeras décadas de vida constitucional. Unos lo consideraron el puntapié inicial para comenzar a dar forma a una jurisprudencia propia. Otros, como Sarmiento, lo juzgaron como modelo más acabado y que como

34 Una argumentación similar desarrolló el diputado por Buenos Aires Carlo Keen en la sesión del 6 de agosto, recuperando fuentes clásicas como El federalista, junto con el fallo Luther vs. Borden, y fuentes modernas como las obras de Paschal y Pomeroy. Congreso Nacional/Diputados, 1869, 224 y ss. (sesión del 6 de agosto).

35 Congreso Nacional/Senado, 1869b, 21 (sesión del 19 de junio).

36 Ibidem, 140 (sesión del 23 de junio). 
tal debía ser adoptado cabalmente y sin vacilaciones. De una forma u otra, todos dirigieron su mirada a la experiencia del Norte para sortear las dificultades y desacuerdos que trajeron consigo las nuevas instituciones. Las traducciones de varias obras utilizadas en este debate por los representantes en el Congreso fueron publicadas en esos mismos meses. En 1868 apareció la primera versión completa en español de El Federalista; en 1869 se publicó Poderes ejecutivos del gobierno de los Estados Unidos, tomado de An Introduction to the Constitutional Law of the United States de John Norton Pomeroy; finalmente, en 1870 se publicó Constituciones de algunos Estados de la Unión Americana. Estas traducciones, como otras elaboradas durante esos años, fueron estimuladas directa o indirectamente por la voluntad de Sarmiento, como expresaba un decreto de 1869:

$1 .^{\circ}$ Que es un deber de todo gobierno ilustrar al pueblo de sus derechos por medio de libros que expliquen la Constitución política del país; lo mismo que en sus deberes: por la enumeración de las prerrogativas de los poderes públicos; $2 .^{\circ}$ Que muchos de los disturbios que han tenido lugar en la República, nacen de la confusión de facultades y conflictos de los poderes de los estados federales, desconociendo las atribuciones del gobierno general; dudando de la constitucionalidad de sus actos; $3 .^{\circ}$ Que por la similitud entre nuestra Constitución y la de los Estados Unidos de Norte América conviene a falta de libros originales traducir los comentadores más notables y modernos de ésta. ${ }^{37}$

En efecto, «la constitución política del país» no se había agotado en la sanción de la carta nacional sino que la edificación de las instituciones por ellas consagradas tomó varias décadas de aprendizaje, debates, desacuerdos y experimentación. ${ }^{38}$ Un aspecto de ese proceso fue la reglamentación del artículo sexto sobre intervenciones. El debate parlamentario de 1869 fue

37 Citado en Levaggi, 1988, 29.

38 Como expresaba el senador por Córdoba Martín Piñero, se trataba «de un derecho nuevo sobre el cual todos estamos estudiando recién e ilustrándonos» y resaltaba los conocimientos adquiridos en el marco de la práctica parlamentaria, recordando que «en 1862 tomaba yo asiento por primera vez en esta Cámara en medio de un cuerpo deliberante; apenas había leído la Constitución sin entenderla perfectamente bien a pesar de que mi inteligencia estaba poco más o menos a la altura de la generalidad de las gentes del país; puesto que en la Convención del año 60 apenas tres o cuatro individuos mostraron que algo habían leído y sabían sobre las instituciones americanas». Y continuaba sobre el tema al día siguiente: «Recuerdo que en la Convención en 1860 cuando se discutía en Buenos Aires la Constitución, tres o cuatro miembros de aquel respetable cuerpo, se podía decir que tenían algunas ideas y jurisprudencia constitucional; los demás muy poco habían y ni aun libros en que estudiar la materia, existían en Buenos Aires. Habían libros como Tocqueville y otros que son más bien historias y viajes, que una discusión precisa sobre la materia, sobre la aplicación práctica de un artículo de la Constitución, o si había sería muy raro el hombre que los poseyese». La diferencia con la familiaridad con que él y sus colegas se expresaban sobre doctrina norteamericana siete años después es notable. Congreso Nacional/ Senado, 1869a, 609-627 (sesión del 21 de agosto). 
el más extenso que se dio sobre esa cuestión durante el siglo XIX y dejó sentados importantes antecedentes para decisiones futuras. Por una parte las polémicas validaron y dieron nuevo impulso a la tarea de traducción y difusión de doctrina norteamericana que continuó en los años siguientes. ${ }^{39}$ Pero también los argumentos de los miembros del Congreso circularon más allá del recinto y pudieron ser recuperados en las décadas posteriores. ${ }^{40}$

Aunque en los años setenta continuaron prevaleciendo las intervenciones por decreto presidencial, esta tendencia se modificó con el establecimiento de un «sistema de hegemonía gubernamental» por parte del Partido Autonomista Nacional (PAN) en $1880 .{ }^{41}$ Ese año resultó un punto de inflexión en la política argentina: entonces se selló la definitiva supremacía política y militar del Estado nacional sobre las provincias, especialmente sobre la poderosa Buenos Aires, tras el triunfo de Julio Roca sobre el gobernador de Buenos Aires, Carlos Tejedor, en las elecciones de presidente - y la derrota de la protesta armada porteña contra esos resultados—, que derivó en la federalización la ciudad de Buenos Aires y la prohibición a los gobiernos de provincia de formar cuerpos militares. Las siguientes décadas estuvieron dominadas por la hegemonía del PAN que buscó clausurar la agitada experiencia política que había caracterizado la vida pública hasta el momento, gobernando con un programa sintetizado bajo el lema de «paz y administración». Durante las presidencias de Julio Roca (1880-1886) y Miguel Juárez Celman (1886-1890) se procuró manejar los conflictos que tuvieron lugar en las provincias informalmente dentro del acuerdo entre las dirigencias que constituían el PAN y lejos de la arena parlamentaria. Entonces solo se dieron cuatro intervenciones en toda la década, y solamente una de ellas por decreto del ejecutivo. Más que de un renovado poder del legislativo, este cambio daba cuenta de las modificaciones en la relación entre los poderes que traía el hecho de que el PAN tuviera una cómoda posición en el Congreso. En esos años no se dieron iniciativas de amplias proporciones en pos de sancionar una reglamentación general e incluso el tema perdió interés en las aulas universitarias donde prácticamente no recibió

39 Zimmermann, 2014.

40 El Senado publicó La cuestión San Juan donde constaban las polémicas de varias sesiones sobre la intervención a aquella provincia. Asimismo, la Revista de Legislación y Jurisprudencia publicó un extenso artículo denominado «Facultad de Intervenir» en la sección de Derecho Constitucional donde se reprodujeron los proyectos de ley y parte de los debates sostenidos en las cámaras.

41 El PAN se organizó como una constelación de líderes provinciales a fines de los años de 1870. En ella confluyeron sectores dirigentes de varias provincias y del partido autonomista de Buenos Aires. La expresión entrecomillada pertenece a Botana, 1998. 
atención de los doctorandos. ${ }^{42}$ Pero el problema volvió a surgir con fuerza en los años noventa, cuando aparecieron las primeras grietas en el régimen de hegemonía del PAN.

\section{Debates y críticas sobre el modelo norteamericano: alcances y límites de una nueva cuestión «moral»}

Durante la década de 1890 las referencias a los Estados Unidos en las cámaras se modificaron y comenzaron a caer en desuso, al tiempo que las reflexiones sobre la propia experiencia argentina comenzaron a ocupar un lugar más relevante. En ese marco cambió el rol que el experimento norteamericano jugó en los debates parlamentarios locales. En las décadas de los sesenta y setenta el modelo constitucional y la legislación de aquel país habían resultado fuentes textuales para la elaboración de un corpus legal. En los noventa, en cambio, no se buscó calcar su jurisprudencia sino evaluar y contrastar sus particularidades históricas. Esta nueva perspectiva ponderaba las características de la sociedad norteamericana por sobre su aporte jurídico. En tono optimista, se mostraba la posibilidad del éxito asociada a esa legislación y a esa estructura social, mientras que en tono pesimista se negaba la posibilidad de que esa jurisprudencia fuera adecuada para un tipo de sociedad como la argentina.

Estos cambios en los términos de la discusión y en el uso del ejemplo norteamericano en las cámaras se hicieron evidentes en el segundo momento de debate sobre la reglamentación del artículo sexto que se dio entre 1893 y 1894 . Entonces la situación política del país había cambiado. Aunque el Estado nacional había logrado afirmar su autoridad frente a las provincias en 1880, en los años noventa aparecieron nuevos desafíos que se vinculaban a la política partidaria y que se materializaron en un ciclo de revoluciones, protestas y disturbios protagonizados por un nuevo partido opositor, la Unión Cívica Radical (UCR), ${ }^{43}$ que llevaron a que en 1893 se interviniera media docena de provincias y se dictara el estado de sitio en todo el país. ${ }^{44}$ Tras el fracaso en sancionar una ley reglamentaria o una orgánica en 1869, no existía una normativa vigente sobre el procedimiento de

42 Chiaramonte y Buchbinder, 1992.

43 Sobre la formación de la UCR en la década de 1890 y sus impugnaciones al régimen del PAN: Alonso, 2000.

44 Botana, 1998. Alonso, 2010. 
las intervenciones, pero sí el antecedente de que durante los años ochenta habían sido decididas casi en su totalidad en el Congreso. En esta crítica coyuntura de 1893, las intervenciones también fueron por decisión parlamentaria, pero en su ejecución se hicieron evidentes intersticios y recursos que el ejecutivo conservaba para fortalecer sus facultades, como por ejemplo su potestad para instruir a los interventores.

Por este motivo, durante 1894 el Congreso debatió extensamente el proceder del ejecutivo en las intervenciones del año anterior y la necesidad de reglamentar las atribuciones del gobierno nacional en la materia. ${ }^{45} \mathrm{~A}$ diferencia de 1869 , cuando las disputas políticas fueron presentadas como fricciones entre poderes nacionales o entre el gobierno central y las provincias, quienes lideraron los debates en los noventa colocaron en el centro de las controversias los conflictos partidarios entre el gobierno y sus críticos. ${ }^{46}$ En 1894 se incorporaron a las cámaras doce diputados y un senador, Bernardo de Irigoyen, de la UCR ${ }^{47}$ Las propuestas de reglamentación de las intervenciones partieron de estos legisladores de la nueva oposición que elaboraron un proyecto de ley que buscaba terminar con los intersticios reglamentarios que posibilitaban la injerencia discrecional de los distintos poderes. Como en 1869, establecía la necesidad de que toda intervención nacional fuera autorizada por el Congreso y, si esta sucedía durante el receso, que fuese inmediatamente refrendada al reiniciarse las sesiones. Instauraba la necesidad de una justificación de los motivos y objetivos de la intervención por parte del gobierno nacional y del poder provincial que la requiriese, y establecía que solo se podían reponer las instituciones republicanas cuando hubieran sido «revocadas por instituciones contrarias». ${ }^{48}$ Además fijaba límites a la capacidad de acción del interventor en asuntos locales y establecía una instancia judicial para reprobar su comportamiento. ${ }^{49}$

45 Sobre el papel que tuvo el Congreso en el primer quinquenio de la década ver Gallo, 1980, y Alonso, 2000.

46 Esto no significa que los conflictos partidarios hubieran estado ausentes a fines de los años sesenta, ni que para los años noventa hubieran desaparecido las disputas entre el gobierno central y las provincias, sino que en la expresión de las controversias el acento fue puesto en una u otra cuestión.

47 Si bien Irigoyen formaba parte de la nueva oposición no era un recién llegado a la política. Había sido miembro del gabinete de ministros durante las presidencias de Nicolás Avellaneda (18741880) y Julio A. Roca (1880-1886), y había sido diputado nacional por la provincia de Buenos Aires.

48 En la segunda mitad del siglo XIX gran parte de las discusiones sobre la legalidad de las intervenciones federales se vincularon al debate sobre en qué consistía específicamente la forma republicana de gobierno que el poder federal garantizaba. Por esos motivos con esta formulación se trataba de poner fin a esa opacidad que dejaba un amplio margen de arbitrio en la consideración de las situaciones particulares.

49 Ministerio del Interior, 1933, 109-112. 
El proyecto pasó a tratativa de la comisión de negocios constitucionales pero su tratamiento no fue retomado, probablemente por ser una iniciativa opositora. Por esos motivos, el senador radical Bernardo de Irigoyen forzó una discusión en la materia solicitando la interpelación al ministro de Interior para que rindiera cuenta del accionar del ejecutivo en las intervenciones.

La formulación de estas iniciativas radicales hizo evidentes algunos cambios en el rol de Estados Unidos como referente. A diferencia de los debates del 69, donde se comenzaba exponiendo el ejemplo norteamericano como base necesaria para abordar luego los desafíos nacionales, el proyecto radical para regular las intervenciones recurría solo a ejemplos locales, «reglamentando exclusivamente aquellos puntos en que es más posible el acuerdo, porque su interpretación surje clara y evidentemente de la letra y del espíritu de nuestra Constitución». ${ }^{50}$ Esta opción daba cuenta de una novedad en la práctica parlamentaria. En vez de exponer en un comienzo la referencia norteamericana como punto de partida para cualquier discusión, esta era colocada al final como ejercicio comparativo con lo propuesto. La estructura argumentativa sumaba ahora un conjunto de capas que solidificaban el argumento: la historia del país, los antecedentes políticos, los motivos, otros trabajos preparatorios y doctrinas, y finalmente un ejercicio comparativo con legislación o comentaristas extranjeros, que en el caso del federalismo remitían privilegiadamente a los Estados Unidos. ${ }^{51}$ Esa estructura fue utilizada tanto por los legisladores opositores como por un ministro nacional, Wenceslao Escalante, que fue interpelado por la cámara de diputados sobre su accionar en materia de intervenciones. Entonces el ministro avanzó sobre los antecedentes nacionales y al llegar a la parte de la comparación con la legislación extranjera, optó por soslayarla (al igual los legisladores radicales) con las siguientes palabras:

No podemos, en este caso, referirnos o darle gran importancia a la interpretación comparativa con las instituciones análogas de los Estados Unidos, porque, aparte de que este criterio no está tan de moda como en los primeros tiempos de nuestras aplicaciones de la constitución, en que, a falta de antecedentes propios y de conocimientos de la índole del funcionamiento de los poderes dentro de las instituciones que nos habíamos dado, se recurría a buscar cómo, en análogas circunstancias, se había procedido en aquel país. ${ }^{52}$

50 Congreso Nacional/Diputados, 1894, 568 (sesión del 12 de junio).

51 Este modelo de fundamentación no era nuevo y había sido ampliamente utilizado por Juan B. Alberdi. Véase Vannossi, 2013, 24.

52 Congreso Nacional/Diputados, 1893, 105 (sesión del 12 de junio). 
Este comentario de Escalante era un síntoma del cambio del lugar de referencia jurídica del modelo norteamericano, pero también una fuerte sugerencia en pos de abandonarlo por completo. Pues aunque la apelación a los Estados Unidos estaba pasada de moda, en los debates parlamentarios sobre las intervenciones se continuaba remitiendo a ella, aunque en menor grado y erudición que en 1869, y también con propósitos distintos.

¿En qué casos aparecía ahora el ejemplo norteamericano? En primer lugar continuó siendo una cita de autoridad en discursos preparados de antemano como las interpelaciones a ministros o la fundamentación de proyectos de ley. Allí la comparación con esa jurisprudencia fue más frecuente y literal, probablemente por la posibilidad de preparar con anticipación los discursos y consultar las obras. En ese marco la doctrina norteamericana fue usada para dar un enfoque más universal a la definición de conceptos como «forma republicana de gobierno» o para indagar las fuentes de los artículos de la Constitución nacional.

En segundo lugar, se recuperaron ejemplos históricos como los casos de Rhode Island y Luisiana. El primero ya había sido utilizado en los debates de 1869. El segundo remitía a un conflicto posterior que tuvo lugar durante la presidencia de Hayes (1877-1881). Entonces se habían formado en Luisiana dos legislaturas y dos gobiernos, uno republicano y otro demócrata. El presidente, que era amigo político del contendiente republicano, envió una comisión para que se encargase de reconocer con independencia cuál era la legislatura legítima, que resultó ser la demócrata, y el gobernador elegido fue entonces un opositor.

Estos dos casos fueron constantemente rememorados en las cámaras por varios motivos. Por una parte, esas experiencias formaban parte de un conjunto de referencias más sencillas de recordar que los tratados jurídicos y se hallaban disponibles tanto en los libros de historia norteamericana como en los propios diarios de sesiones que los legisladores tenían a su disposición. ${ }^{53}$ Por otra, la posición asumida por el gobierno federal, especialmente en el caso de Luisiana, permitía llevar la discusión más allá de la arena jurídica hacia al plano de cuál era el comportamiento político moralmente aceptable de un presidente.

Para debatir este último punto, la moral presidencial, también se hizo referencia a la guerra de Secesión y la actuación del gobierno federal.

53 Por ejemplo, Historia de los Estados Unidos. Desde su primer período hasta la administración de Jacobo Buchanan, de Jesse Ames Spencer, editada en Barcelona en 1870 y disponible en Buenos Aires. 
Durante su interpelación, el ministro del Interior, Manuel Quintana, fundamentó las intervenciones y el estado de sitio de 1893 en función de la existencia de una situación de conmoción política que ponía en peligro al país y que, a su juicio, demandaba la necesidad de concentrar en el ejecutivo mayor capacidad de acción. Desde la vereda opuesta, la guerra de Secesión le sirvió al senador radical Bernardo de Irigoyen de punto de comparación en negativo, para refutar la supuesta excepcionalidad de la situación de crisis del momento y mostrar que en el caso nacional no estaba en riesgo la integridad del país, sino que se trataba más bien de disputas locales:

Y no hablemos de la guerra de secesión en los Estados Unidos. No puede traerse a mención, cuando se están discutiendo las contiendas domésticas de los estados. Aquella fue una gran revolución, la más imponente, la más tremenda que ha presenciado la humanidad [...] y no hemos de traer esto como doctrina para decidir si el doctor García debió seguir gobernando quince días más o menos en la provincia de Tucumán. ${ }^{54}$

Al igual que en 1869, también la vida pública de Lincoln aparecía en estos debates como un ejemplo a imitar. Sin embargo lo que subrayaba Irigoyen, a diferencia de lo que había hecho Sarmiento un cuarto de siglo antes, no era su accionar frente a los estados sino su comportamiento. En contraposición a los debates de 1869 , en los cuales la figura de Lincoln aparecía asociada a las formas de aplicación de la normativa y alimentaba una discusión organizada en función de emular las leyes norteamericanas y discutir sus fuentes, en 1893 era su personalidad lo que se consideraba central:

lo he promovido para decir al Presidente de la República, con la ingenuidad con que soy capaz de hablar en esta situación, en la que no expongo consideración que no sea respetuosa, que abra el libro de la Constitución, que abra el libro de los Estados Unidos, que abra la vida de Lincoln, que estudie los actos de aquel gran hombre; no es una ofensa, señor Presidente, que un Senador diga al jefe de la República que estudie los antecedentes de un hombre justo, bueno, santo, cuyo nombre la humanidad ha inscripto en el templo de la inmortalidad. ${ }^{55}$

Lincoln, el hombre, era la garantía del funcionamiento democrático norteamericano. Sus cualidades morales habían guiado sus acciones justas y aparecían ahora resaltadas como ejemplo a seguir por sobre la letra de las leyes. Así, la misma situación política fue recuperada por Irigoyen 25 años

54 Congreso Nacional/Senado, 1894, 555-556 (sesión del 27 de septiembre).

55 Ibidem, 581 (sesión del 28 de septiembre). 
después para elaborar un argumento contrario a Sarmiento, señalar la excepcionalidad de la situación separatista y mostrar otras situaciones de la política norteamericana en donde

el presidente no intervino militarmente; por el contrario, tuvo mucho cuidado de dar este hermoso espectáculo; fue al Congreso a dar cuenta del desenlace de aquellos sucesos, y a decirle con justísima satisfacción: «No he movido las fuerzas nacionales, no he hecho intervenir al ejército en esta cuestión; se ha resuelto por el sentimiento, por el buen sentido, por las conveniencias mismas del estado». ${ }^{56}$

En tercer lugar, en ocasiones especiales se remitió a la jurisprudencia estadounidense (principalmente a lo que en 1869 se denominaba «autores modernos») para evaluar la actuación del ejecutivo en tiempos de crisis. Por ejemplo, Irigoyen procuró ver si en «los constitucionalistas americanos, de que tanto hablamos, aunque no siempre procedamos de acuerdo con ellos, había algo que justificase este procedimiento. Encontré que yo tengo razón, que esto no es propio». ${ }^{57}$ En este caso el senador tomó como referencia Gobierno y derecho constitucional: o sea un examen sobre el origen y los límites de la autoridad gubernativa según la teoría americana de Joel Tiffany, ${ }^{58}$ a quien presentó como un «escritor autoritario, propenso a sostener y ampliar, hasta donde es posible las facultades presidenciales». ${ }^{59}$ Esa obra, que había sido escrita tras la guerra de Secesión, también le sirvió de ejemplo para establecer los límites morales de la acción política legítima por parte del presidente estableciendo que no era admisible que presionara a gobernadores y funcionarios. Del mismo modo, remitió a una sentencia de la Corte de los Estados Unidos para establecer la diferencia entre las funciones presidenciales en tiempos de paz o de guerra y los límites para la movilización de tropas e intervenciones militares, explicando que: «En tiempo de paz, cuando las leyes son o pueden ser ejecutadas sin intervención del presidente con la fuerza militar, no tiene derecho para intervenir invocando el carácter de comandante en jefe». ${ }^{60}$ Finalmente citó Poderes de Guerra bajo la Constitución de Estados Unidos de Whiting para refutar el derecho del presidente de intervenir militarmente en las provincias:

\footnotetext{
56 Ibidem, 556 (sesión del 27 de septiembre).

57 Ibidem, 567 (sesión del 28 de septiembre).

58 A Treatise on Government and Constitutional Law being An Inquiry into the Source and Limitation of Governmental Authority according to the American Theory, publicado en $1867 \mathrm{y}$ traducido en Argentina en 1874.

59 Congreso Nacional/Senado, 1894, 567 (sesión del 28 de septiembre).

60 Ibidem, 578.
} 
El Congreso puede dar reglas y ordenanzas relativas a las capturas y para el gobierno y reglamentación de las fuerzas de mar y tierra cuando se hallan en servicio; y esas reglas y ordenanzas serán obligatorias para el Presidente, cuyo deber es velar por el fiel cumplimiento de todas las leyes y constituciones nacionales, y esto a pesar de que él es el jefe supremo del ejército. ${ }^{61}$

Sin embargo, a diferencia de los años sesenta, las citas textuales ya no resultaban comunes. Al calor del debate, las referencias de autoridad funcionaban casi como escudo argumentativo. En general no se utilizaban citas puntuales, sino que se apelaba al apellido de los autores sin dar cuenta de sus lineamientos, de la mano de intervenciones como la siguiente del diputado oficialista por Entre Ríos Osvaldo Magnasco: «Perfectamente; y yo le cito la autoridad de Rossi, que ha sido mal citado por el señor diputado, y la autoridad de Story sobre todas las cosas». ${ }^{62}$ Esta costumbre de solo citar los nombres de los juristas o publicistas daba cuenta de la falta de conocimiento general que la cámara tenía sobre esas fuentes. Las citas eran frecuentemente mal utilizadas y en ocasiones se afirmaba, como lo hizo el legislador cordobés Tristán Almada, que «por mi parte no puedo hablar en nombre de la una ni de los otros. Estoy desposeído de toda ciencia» ${ }^{63}$ La licencia para usos como el de Magnasco parecía fundarse en las credenciales públicas de algunos de los oradores, que ante un pedido de ampliación podían presentar esas fuentes adecuadamente. Estas credenciales eran refrendadas por gestos tales como solicitar un cuarto intermedio para realizar «algunas consultas al respecto, de textos de derecho constitucional, aplicables al caso, para fundar la doctrina». ${ }^{64}$

Para la década de 1890 el lugar retórico, histórico y jurídico del modelo norteamericano estaba cambiando también en otros sentidos. Por una parte, surgieron otros modelos internacionales para reflexionar sobre el sistema político argentino. ${ }^{65}$ También se modificó la temática de las obras norteamericanas traducidas. Como señala Zimmermann, entonces se atendió a tratados de administración pública más que a estudios constitucionales, ya que aquellos satisfacían la creciente necesidad de reflexionar sobre el ordenamiento burocrático del Estado ${ }^{66}$ En tercer lugar, se comenzó a remitir a una «tradición» de constitucionalistas argentinos: un conjunto de publicistas, sus tesis, folletos y discursos que ofrecían un bagaje teórico

\footnotetext{
61 Idem.

62 Congreso Nacional/Diputados, 1893, 345 (sesión del 30 de julio).

63 Ibidem, 368 (sesión del 1 de agosto).

64 Ibidem, 331 (sesión del 30 de julio). La frase corresponde al diputado Magnasco.

65 Como por ejemplo el de la Alemania prusiana. Véase Botana, 1998, 125.

66 De la mano de estas transformaciones, desde 1894 la enseñanza del Derecho Constitucional se separó por completo del Derecho Administrativo. Tanzi, 2011.
} 
propio para contraponer a los tan mentados tratadistas norteamericanos. ${ }^{67}$ Este nuevo recurso se vinculaba a la consolidación de la cátedra de Derecho Constitucional de la Universidad de Buenos Aires como usina de elaboración teórica desde 1869. Sus titulares habían inaugurado una tradición de reflexión sobre la organización y el funcionamiento federal argentino. Estos cambios se hicieron evidentes en sus propios programas desde fines de la década de 1870, cuando se comenzó a prestar mayor atención a los «antecedentes nacionales» que hasta el momento se hallaban por completo ausentes del currículo. ${ }^{68}$ Los debates sobre las intervenciones recuperaron los manuales elaborados por esa cátedra así como las circunstancias de cada caso y los antecedentes de otras intervenciones en el país. Así, para la década de los noventa, se reforzaba la línea que Francisco Ramos Mejía había desarrollado en El federalismo argentino (1889), en la que para reflexionar sobre el federalismo nacional recurría al análisis de sus antecedentes históricos, a la llamada constitución histórica del país. ${ }^{69}$ Como expresaba el diputado opositor por Mendoza, Agustín Álvarez, para reglamentar cualquier artículo constitucional se debía considerar que la carta contenía tres dimensiones distintas: «primera, la forma; segunda, el fondo; tercera el espíritu del pueblo para el cual fue hecha, el espíritu norteamericano del cual es una emanación». ${ }^{70}$ Este lenguaje espiritual, bastante vago de aprehender, daba cuenta de nuevos motivos que afectaron la concepción del derecho, no tanto en su forma doctrinaria sino en el modo en que este era concebido en relación a la sociedad. Estos cambios se vincularon a la difusión a fin de siglo de nuevas propuestas filosóficas, científicas y teóricas para pensar la realidad social y política, que reunieron elementos positivistas, naturalistas, espiritualistas, esteticistas, historicistas y románticos. ${ }^{71}$

Los debates daban cuenta de esas novedades, subrayando que la elaboración de leyes debía tomar como referencia la sociedad en la cual se pretendía aplicarlas, sus características e historia. Como sostenía Álvarez «esos tratadistas de derecho constitucional [los norteamericanos] se ocupan de decir cómo deben ser las cosas», por lo que se separaban de la realidad

67 Véase por ejemplo la intervención del diputado por la Capital Federal, Pascual Beracochea. Congreso Nacional/Diputados, 1893, 345 (sesión del 30 de julio).

68 Tanzi, 2011.

69 Chiaramonte y Buchbinder (1992) han sugerido que la tesis de Ramos Mejía no encontró demasiado eco en la literatura política y constitucionalista de la época. Sin embargo, sus argumentes fueron retomados de manera recurrente en el recinto parlamentario.

70 Congreso Nacional/Diputados, 1893, 341 (sesión del 30 de julio).

71 Terán, 2000. 
sobre cómo eran en efecto esas cosas. ${ }^{72}$ La realidad argentina tenía a su juicio características que le eran propias y que debían ser consideradas primordialmente. Así, por más que se había «puesto a estudiar a Story, a Paschall y a esos caballeros que han comentado la Constitución de los Estados Unidos, para darme cuenta de lo que sucede en mi tierra», se había dado cuenta de que «lo que ellos dicen nada, absolutamente nada tiene que ver con lo que pasa aquí. De lo que se ocupan, es de una cosa muy distinta». ${ }^{73}$ Este argumento daba por tierra con cualquier otro basado en constitucionalistas extranjeros y habilitaba «buscar la explicación de nuestros hechos en Taine y en la historia argentina del doctor López, más que en los precedentes de la constitución norteamericana». ${ }^{74}$

Esta línea crítica permitía subrayar las particularidades de la Argentina, su historia, sus costumbres políticas y, por lo tanto, la diferencia en la conducta personal de los hombres, en el modo de ser del país y en el comportamiento político de los partidos. Esta comparación, en negativo, también fue esgrimida por el ministro del Interior, Manuel Quintana, quien frente a los ejemplos de políticas de no intervención en los Estados Unidos respondía:

¡Ojalá nosotros pudiéramos ostentar idéntica o más tranquila historia constitucional! Y para demostrar la inaplicabilidad del recuerdo del señor diputado, me bastará preguntarle: ¿cuantas veces, en el curso de ese siglo, se han derrocado, en los Estados Unidos, los poderes de tres provincias, amenazando el asiento del gobierno nacional, y perturbado, además, otra de las provincias fronterizas de la República? ¿Cuándo, en los Estados Unidos, durante ese siglo de vida independiente, un gobernador de territorio federal ha denunciado el propósito de convulsionar el territorio de su mando, abusando de lo escaso e inerme de las fuerzas policiales que lo guardan? ${ }^{75}$

Pero ese tipo de comparación fue utilizada también en términos positivos por el senador Irigoyen, quien consideró que «las perturbaciones del país [podían remediarse] con una política moderada, sensata, que se inspirase en los ejemplos de los Estados Unidos». ${ }^{76} \mathrm{Al}$ igual que sus contrincantes, el radical tomó como punto de partida la historia pero desde un enfoque

72 Congreso Nacional/Diputados, 1893, 671 (sesión del 23 de septiembre).

73 Idem. La discusión sobre la particularidad de la historia argentina o la aplicabilidad del modelo norteamericano tuvo lugar también en la prensa. Alonso, 2010, 341-342.

74 Congreso Nacional/Diputados, 1893, 671. Los orígenes de la Francia contemporánea de Taine tuvo amplia circulación en Argentina en los años de 1880 y fue recuperada en la cátedra de Derecho Constitucional de la Universidad de Buenos Aires. Al igual que en el análisis de Taine, en el cual raza, medio y momento determinaban la historia revolucionaria francesa, el titular de la mencionada cátedra, Lucio V. López, otorgó un lugar central a la historia local, marcando las diferencias entre la colonización inglesa y la española. Devoto, 1992. Chiaramonte y Buchbinder, 1992.

75 Congreso Nacional/Diputados, 1893, 436 (sesión del 15 de agosto).

76 Congreso Nacional/Senado, 1894, 553 (sesión del 27 de septiembre). 
más universalista, alejándose de las particularidades históricas y presentando a los Estados Unidos como la meta de todo progreso civilizatorio, como el modelo de lo que debía ser hecho para alcanzar un Estado nacional potente y abierto al progreso. En su interpretación, las intervenciones de los Estados Unidos resultaban el modelo a seguir, no porque debiera copiarse sus leyes, sino porque debía emularse su dinámica. Por ello remitió de manera laxa a la historia americana, pues allí «se desenvuelven maravillosamente bajo la base del profundo respeto a la autonomía de los Estados, al mantenimiento del sentimiento nacional que yo siempre he sostenido; pero, al mismo tiempo, el respeto, la consideración, diré así por la soberanía, por las prerrogativas constitucionales de los Estados». ${ }^{77}$

\section{Conclusiones}

En la segunda mitad del siglo XIX se dieron controversias recurrentes en la Argentina sobre el funcionamiento efectivo del régimen federal y sobre las atribuciones del gobierno central en las provincias. Los dos mayores momentos de debate parlamentario tuvieron lugar a comienzos de la presidencia de Sarmiento en 1869 y tras la crisis política de 1893. Esas polémicas evidenciaron los límites concretos del consenso materializado en la Carta nacional y expresaron desacuerdos que combinaron en grado diverso cuestiones políticas e institucionales. Mostraron, también, los efectos de la falta de una jurisprudencia uniforme sobre cuestiones centrales del funcionamiento institucional.

En el marco de ese vacío, la experiencia norteamericana funcionó como un ejemplo recurrente. Si bien en los debates aparecieron, en menor medida, menciones a Gran Bretaña o Suiza, los Estados Unidos resultaron el referente último e inapelable. Pero más que significar que en esas décadas circuló una sola forma para pensar el federalismo, este artículo ha buscado mostrar que ese ejemplo reunió en sí mismo varios «modelos» para imaginar alternativas de organización. Esas diferencias no nacían únicamente de las diversas miradas de quienes recuperaban en Argentina esa legislación, sino que remitían también a cambios y debates concretos que en esas décadas se dieron en aquella nación.

Un elemento común en los dos momentos fueron las tensiones y disputas entre ejecutivo y legislativo para definir sus facultades y

77 Ibidem, 554. 
prerrogativas. En los dos casos aparecieron síntomas de esa fricción pero con diferencias. En 1869 el presidente vetó las leyes del Congreso pero no contó con el poder suficiente para imponer su propuesta de ley reglamentaria que brindaba mayores poderes al ejecutivo. En cambio, para los años noventa no aparecieron propuestas en esa dirección y se aceptaba que cada intervención fuera dictada por el Congreso. Ese consenso, que se vinculaba a la posición hegemónica del PAN, fue horadado por la crisis de 1893, que evidenció algunos intersticios reglamentarios aprovechados por el ejecutivo para extender sus facultades.

En cambio, un elemento que diferenció los dos momentos fue el lugar que ocupó Estados Unidos en esas disputas. Durante las primeras décadas de vida constitucional la legislación norteamericana funcionó como uno de los principales referentes para informar la articulación entre el Estado nacional y las provincias. Entonces, la experiencia inmediata de la guerra de Secesión y el accionar de Lincoln frente a lo que consideró una rebelión ilegal en los estados del Sur, coincidía de algún modo con los objetivos e intereses de Sarmiento: su voluntad de avanzar en la afirmación de la autoridad nacional frente a focos alternativos de poder en las provincias y de organizar un Estado central fuerte.

En estos debates la legislación norteamericana estuvo presente de un modo contundente. Tanto los integrantes del ejecutivo nacional como los legisladores que intervinieron estaban al tanto de las novedades publicadas, de los fallos de la Corte Suprema y de los debates parlamentarios en los Estados Unidos y los utilizaron para articular y fundamentar sus proyectos e intervenciones. Los libros originales y las traducciones fueron llevados a las cámaras donde los legisladores los citaron en extenso. Esa centralidad nacía de los desafíos que los legisladores experimentaban a la hora de legislar algunas instituciones y prácticas básicas del diseño constitucional sin disponer de la ayuda de antecedentes nacionales y con conocimientos —más estrechos o más profundos en distintos casos - sobre derecho constitucional. Como expresaba Sarmiento, gran parte de las dificultades surgían de «no estar entendidos sobre el sentido que encierran las palabras que expresan cosas que son esenciales al gobierno». ${ }^{78}$ En ese marco, la difusión de tres clases de insumos como las fuentes clásicas, los autores considerados «antiguos» y los «modernos», resultaron centrales no solo para imaginar los contornos del régimen federal, sino en un sentido más general para nutrir el proceso de aprendizaje que se estaba llevando a cabo en la propia práctica parlamentaria.

78 Sarmiento, 1900, 82. 
El segundo momento analizado, de mediados de los noventa, la cuestión en disputa no apuntaba tanto a establecer las atribuciones del gobierno central frente a los poderes provinciales sino a redefinir un funcionamiento institucional y consensuar prácticas efectivas que hacían al régimen federal, en el marco de una crisis política profunda y de la aparición de un fuerte partido opositor. Entonces los Estados Unidos ya ocupaban un lugar referencial consolidado en el imaginario político y cultural. El acervo bibliográfico, traducido en las décadas anteriores, conformaba parte de un saber legislativo y daba forma a un lenguaje y a una retórica de discusión por todos conocidos. Sin embargo, dos cambios comenzaron a hacerse evidentes. Por una parte, la erudición de los primeros años de vida constitucional ya no resultó moneda frecuente; por otro, algunos sectores comenzaron a considerar que ese referente resultaba arcaico e inadecuado para pensar los problemas y que debía atenderse a los antecedentes «nacionales». ${ }^{79}$ Entonces empezó a prestarse más atención a las características de la sociedad estadounidense que a las de su producción jurídica. Aunque continuaron siendo usadas sus citas de autoridad, especialmente en aquellos discursos que podían ser preparados con antelación, no fueron centrales al debate.

En esa instancia no fue la legislación del Norte, sino el comportamiento político de sus líderes, lo que cobró relevancia como tópico en la cámara y lo que comenzó a compararse con la realidad local. Quienes siguieron ponderando positivamente el experimento norteamericano, vieron en él a aquella sociedad que había logrado llevar a su mejor expresión los dos valores centrales del mundo contemporáneo occidental: la democracia y el progreso. Otros, que subrayaron las diferencias con la realidad argentina, encontraron en las modalidades de la sociedad estadounidense la prueba irrefutable de la incompatibilidad de su legislación con la situación nacional. En este marco los Estados Unidos, más que cumplir una función de talismán, ${ }^{80}$ funcionaron como un horizonte político añorado.

Recibido el 30 de octubre de 2015 Segunda versión el 16 de junio de 2016

Aceptado el 27 de julio de 2016

79 Sobre la relación entre la apelación a los antecedentes propios y la conformación de un ideario excluyente de nación: Bertoni, 2001.

80 Jonathan Miller ha sugerido que la Constitución norteamericana funcionó como autoridad talismánica en la Argentina decimonónica, en la medida en que la adopción de ese documento se basó en el presupuesto de que si eran seguidas sus prescripciones podrían superarse milagrosamente los problemas de la organización nacional. Miller, 1997, 1488-1489. 


\section{Referencias bibliográficas}

Adelman, Jeremy, «Between Order and Liberty: Juan Bautista Alberdi and the Intellectual Origins of Argentine Constitutionalism», Latin American Research Review, 42:2, Pittsburgh, 2007, 86-110.

Aguilar Rivera, José Antonio, En pos de la Quimera: reflexiones en pos del experimento constitucional atlántico, Madrid, Fondo de Cultura Económica, 2000.

Aguilar Rivera, José Antonio, Ausentes del universo. Reflexiones sobre el pensamiento político hispanoamericano en la era de la construcción nacional, 1821-1850, México, Fondo de Cultura Económica, 2012.

Alonso, Paula, Entre la revolución y las urnas. Los orígenes de la Unión Cívica Radical y la política argentina en los años noventa, Buenos Aires, Sudamericana, 2000.

Alonso, Paula, Jardines secretos, legitimaciones públicas. El Partido Autonomista Nacional y la política argentina de fines del siglo XIX, Buenos Aires, EDHASA, 2010.

Alonso, Paula y Bragoni, Beatriz, El sistema federal argentino. Debates y coyunturas (1860-1910), Buenos Aires, EDHASA, 2015.

Bender, Thomas, A Nation among Nations: America's Place in World History, New York, Hill and Wang, 2006.

Bertoni, Lilia Ana, Patriotas, cosmopolitas y nacionalistas. La construcción de la nacionalidad argentina a fines del siglo XIX, Buenos Aires, Fondo de Cultura Económica, 2001.

Botana, Natalio, La Tradición Republicana. Alberdi, Sarmiento y las ideas políticas de su tiempo, Buenos Aires, Sudamericana, 1984.

Botana, Natalio, «El federalismo liberal en Argentina: 1852-1930», en Carmagnani, Marcelo (coord.), Federalismos latinoamericanos: México, Brasil, Argentina, México, Fondo de Cultura Económica, 1993, 224-259.

Botana, Natalio, El orden conservador. La política argentina entre 1880 y 1916, Buenos Aires, Sudamericana, 1998.

Bragoni, Beatriz y Míguez, Eduardo (eds.), Un nuevo orden político. Provincias y Estado Nacional, 1852-1880, Buenos Aires, Biblos, 2010.

Chiaramonte, José Carlos y Buchbinder, Pablo, «Provincias, caudillos, nación y la historiografía constitucionalista argentina, 1853-1930», Anuario IHES, 7, UNICEN, Tandil, 1992, 93-120.

Congreso Nacional/Diputados, Cámara de Diputados. Año 1869, Buenos Aires, La Tribuna, 1870.

Congreso Nacional/Diputados, Diario de Sesiones de la Cámara de Diputados, Buenos Aires, Compañía Sud-Americana de Billetes de Banco, 1893.

Congreso Nacional/Diputados, Diario de Sesiones de la Cámara de Diputados, Buenos Aires, Imprenta del «Congreso», 1894. 
Congreso Nacional/Senado, Sesión de 1869, Buenos Aires, Imprenta del Orden, 1869a.

Congreso Nacional/Senado, Discusión sobre el Proyecto de Ley ordenando la intervención en la Provincia de San Juan, Buenos Aires, La Tribuna, 1869b.

Congreso Nacional/Senado, Diario de Sesiones de la Cámara de Senadores, Buenos Aires, Imprenta del «Congreso», 1894.

Devoto, Fernando, «Taine y Les origines de la France contemporaine», en Devoto, Fernando, Entre Taine y Braudel. Itinerarios de la historiografía contemporánea, Buenos Aires, Biblos, 1992, 11-45.

Gallo, Ezequiel, «Un quinquenio difícil: las presidencias de Luis Sáenz Peña y Carlos Pellegrini», en Ferrari, Gustavo y Gallo, Ezequiel (comps.), La Argentina del ochenta al Centenario, Buenos Aires, Sudamericana, 1980, 215-243.

Halperin Donghi, Tulio, Proyecto y construcción de una nación (1846-1880), Buenos Aires, Ariel, 1995.

Jaffa, Harry, A new Birth of Freedom, Lanham, Rowman \& Littlefield, 2004.

Kent, James, Del gobierno y jurisprudencia constitucional de los Estados Unidos, traducción de Alejandro Carrasco Albano, Buenos Aires, Imprenta de Buenos Aires, 1865.

Levaggi, Abelardo, Dos estudios sobre Vélez Sarsfield, Cuadernos de Investigaciones 5, Buenos Aires, Instituto de Investigaciones Jurídicas y Sociales «Ambrosio L. Gioja», UBA, 1988.

Miller, Jonathan, «The authority of a foreign talisman: a study of U.S. constitutional practice as authority in nineteenth century Argentina and the argentine elite's leap of faith», The American University Law Review, 46:5, Washington, 1997, 1483-1572.

Ministerio del Interior, Intervención federal en las provincias: proyectos de ley orgánica, antecedentes nacionales y extranjeros, Buenos Aires, Talleres Gráficos de Correos y Telégrafos, 1933.

Remorino, Jerónimo (dir.), Anales de Legislación Argentina, años 1852-1880, Buenos Aires, La Ley, 1954.

Sarmiento, Domingo Faustino, Obras Completas. Tomo 32: Práctica constitucional, Buenos Aires, Imprenta y Litografía «Mariano Moreno», 1900.

Sola, Juan Vicente, Intervención federal en las provincias, Buenos Aires, Abeledo Perrot, 1982.

Sommariva, Luis H., Historia de las intervenciones federales en las provincias, Buenos Aires, El Ateneo, 1931.

Sommariva, Luis H., La intervención Federal argentina comparada con la norteamericana y la suiza, Buenos Aires, El Ateneo, 1935.

Tanzi, Héctor J., «La enseñanza de Derecho Constitucional en la Facultad de Derecho de Buenos Aires», Academia. Revista sobre enseñanza del Derecho, 9 , 17, UBA, Buenos Aires, 2011, 85-112. 
Terán, Óscar, Vida intelectual en el Buenos Aires fin-de-siglo (1880-1900), Buenos Aires, Fondo de Cultura Económica, 2000.

Vannossi, Jorge Reinaldo, «Universidad y Derecho Constitucional: Fortunios e infortunios de las Cátedras», Anales de la Academia Nacional de Ciencias Morales y Políticas, XL, Buenos Aires, 2013, 5-52.

Zimmermann, Eduardo, «Historia Global y Cultura Constitucional: Una nota sobre la traducción y circulación de doctrina jurídica en la Argentina del siglo diecinueve», Nuevo Mundo Mundos nuevos [En línea], Débats, 2014, http:// nuevomundo.revues.org/66772 [Consultado: 09/10/2014].

Zorraquín Becú, Ricardo, «La recepción de los derechos extranjeros en la Argentina durante el siglo XIX», Revista de Historia del Derecho, 4, Buenos Aires, 1976, 325-359. 